\title{
sciendo

\section{Sustainable Electronic Product Development in the Baltic Sea Region: A Regional Gap Analysis of Lab Testing Services}

\author{
Robert PHILIPP ${ }^{1,2 *}$, Alise OZARSKA ${ }^{3}$, Gunnar PRAUSE ${ }^{1,2}$ \\ ${ }^{1}$ Wismar Business School, Hochschule Wismar, University of Applied Sciences: Technology, Business and \\ Design / Department of Business Administration, Philipp-Müller-Str. 14, Wismar, 23966, Germany \\ ${ }^{2}$ Tallinn University of Technology, School of Business and Governance: Department of Business \\ Administration, Ehitajate tee 5, Tallinn, 12616, Estonia \\ ${ }^{3}$ Institute of Energy Systems and Environment, Riga Technical University, Azenes iela 12/1, \\ Riga, LV-1048, Latvia
}

\begin{abstract}
Baltic Sea Region represents one of the most innovative areas within Europe with dominating SME sector. In order to keep the region and their product developments competitive it is necessary to safeguard access to high-tech labs including test services. This can be realized only through regional networks of universities - business cooperation. The European Union started the project "Test-4-SME" in 2017 to investigate and promote laboratory networks for testing and assessment of electronic products developed by SMEs from BSR. In a BSR wide online survey, the project consortium identified existing gaps in the regional supply of open laboratories together with shortcomings in services, expertise or test equipment, which is needed by SMEs for electronic product or devices testing. The authors take place in the "Test-4-SME" project, conducted the survey and analysed the regional demand together with the availability of labs for SME sector in the BSR. The study focusses on the research question in which BSR regions there exist already university-business networks of open labs for SME and to which extent the offered services meet the regional demand. Therefore, an approach of a gap analysis is used, which is based on primary data gathered in a BSR wide survey together with expert interviews. The results of the study are discussed in the context of the existing literature and recommendations for future improvements are highlighted.
\end{abstract}

Keywords - Innovation of SME; laboratory tests; regional innovation networks; smart specialization; sustainable production development

\section{INTRODUCTION}

The Baltic Sea Region (BSR) stands for a flagship region in Europe in terms of good economic, social and environmental performance [1]. Following the current "State of the Region Report" [2], the BSR generated in 2015 an annual GDP of about 2000 billion EUR, which is equivalent to $12.5 \%$ of the EU-28 economy. Accordingly, the BSR has a forerunner position among the European Regions. By analysing the Baltic Sea business structures, it turns out that SME sector plays a crucial role as accelerator for innovative products and services of high quality in the frame of the EU Strategy for the BSR [3]. However, this leading

\footnotetext{
* Corresponding author.

E-mail address: robert.philipp@hs-wismar.de
} 
role of SMEs is jeopardized through intensifying globalization, digitalization needs, new social and environmental challenges and fast changing markets.

But among the about 23 million SMEs in Europe there exists the group of hidden champions which is able to cope with the global challenges by operating globally and being market leader in a niche market with high revenues and low level of public awareness. Simon Hermann [4], [5] coined the term "hidden champion" and analysed success factors of these exceptional SMEs. Among several characteristics, he identified high innovation activities that are expressing in high $R \& D$ expenditures and high number of patents as well as in their regional grounding that impact business culture and strategy. In this sense, hidden champions are comparable to more than $99 \%$ of all companies in the EU that are also SMEs and that can be regarded as the backbone and driver of regional and national economies. Under this point of view, the support of SMEs and entrepreneurs, especially in the areas of innovation and product development, makes sense when trying to foster economic growth, to attract regional investments, to enable clusters evolvement and to ensure employability and social integration [3], [6]-[10].

Consequently, these reflections have been considered within the reformed cohesion policy of the European Commission that introduced the "Smart Specialisation Strategy ( $\left.\mathrm{S}^{3}\right)$ " concept, which can be characterized as a place-based approach [11]. By the identification of strategic areas for intervention based both on the analysis of the strengths and potential of the economy and on an Entrepreneurial Discovery Process (EDP) with wide stakeholder involvement. Such a regional development approach opens up new opportunities for interactions between SMEs and regional $R \& D$ institutions for collaborative product development. Several authors studied different forms of regional innovation networks, especially in the context of university-business cooperation and smart specialization approaches, and highlighted promising cooperation models, success stories and best practices [12]-[15].

A special form of university-business cooperation for SME is tackled in the still ongoing EU project "Laboratory network for testing, characterisation and conformity assessment of electronic products developed by SMEs" (TEST-4-SME) - partly-financed by the ERDF (Baltic Sea Region Programme 2014-2020). The TEST-4-SME project brings together SME and research institutions from different BSR countries that are active in the field of electronics and electronic equipment. The aim of the project is to promote and assess various "open lab" cooperation concepts for supporting product development by sharing equipment and services. Starting point was the BSR wide online survey "Mapping Testing Services in Baltic Sea Region" in order to identify and analyse the gaps, e.g. technical expertise or lack of hardware, in testing services as well as to clarify SMEs' needs for electronic product or devices testing services in the BSR.

The authors of the paper take part in the TEST-4-SME project and assessed the outcome of the survey that was executed between October 2018 and February 2019. Beyond the survey results the empirical research comprised expert interviews and case studies in order to identify existing gaps in the regional supply of open laboratories together with shortcomings in services, expertise or test equipment, which is needed by SMEs for electronic product or devices testing. Accordingly, the current research focusses on the research question in which BSR regions there exist already university-business networks of open labs for SME and to which extent the offered services meet the regional demand.

The paper is structured as follow: The second chapter discusses sustainable electronic product development and the related rationale. In the third chapter, the applied research methodology is presented, describing data collection procedure, the data analysis measures 
as well as sample description. Building upon this, the main research results are showcased in the fourth chapter, which embraces a detailed identification and analysis of existing gaps within the BSR in the context of testing services. This article rounds up with a discussion and conclusion, based on the main findings followed by some recommendations or concluding remarks.

\section{Sustainable Electronic Product Development}

The market of electronic products is highly attractive since according to the "Forecast of Global Electronic Components Players Market 2023" [16], the electronic components market will grow with a $3.3 \%$ CAGR (revenue), which represents 403,100 million US Dollar by the year of 2023, compared with 331,200 million US-Dollar in 2017. For SMEs the access to the electronic market is linked with a number of obstacles due to strict requirements and standards that have to be fulfilled when launching new products.

Consequently, during and after the product development process numerous tests have to be realized in order to determine whether a specific product shows compliance to required standards including specific tests for emission, immunity or safety. The necessary testing equipment and multiple testing variables can make the tests quite expensive and time-consuming [17]. Furthermore, high-skilled personnel for executing the tests are required in order to ensure trustworthiness in testing results and certification. In addition to that, tests for specific product properties like magnetic emissions, energy efficiency or environmental compatibility require tailor made testing devices (incl. software) and environments that go far beyond the financial and research capacities of SMEs.

Currently, in some cases there exists already collaborative product development between SMEs and research institutions in the BSR. First, the EU project TEST-4-SME tries to identify and analyse the gaps in technical expertise or lack of hardware for testing services and to clarify SMEs' needs for electronic devices testing services in the BSR. In the sequel, the project shall foster new university-business cooperation models in the field of sustainable electronic product development to support innovative SMEs and to build regional innovation networks for sustainable product development. According to the OECD [18], the circumstance of insufficient match with export product quality, standards and specifications is listed as a top ten barrier for SMEs in the frame of internationalization efforts. Comprehensibly, in particular in case of new and innovative product developments product testing should occur in early development stages in order to avoid later development failures, which might cause huge costs.

On the other hand, particularly early stage product testing (e.g. prototype) causes high costs, which makes it even more difficult for micro and SMEs as well as start-ups to take steps in competition with well-established and global players, due to low or missing return in early product development stages. Furthermore, nowadays, testing labs face high demand and, thus exhibit long waiting lists for electronic manufacturers, which in addition leads to increasing inflexibility on manufacturer side that must rapidly react on fast changing market conditions. Our research results demonstrate that especially in the BSR the accessibility and availability of testing services is not equally distributed among the BSR member states. The research also had a special focus on the situation of testing to climate related issues as well as to energy efficiency due to the importance of these two topics on the EU agenda and current research landscape [19]-[23]. 


\section{Methods ANd Methodology}

\subsection{Data Collection}

Empirical data collection activities were conducted between 1 October 2018 and the 22 February 2019, which represents a total data collection duration of about 5 month ${ }^{1}$. The primary target group had been electronic products producing SMEs that are located in the BSR. The survey comprised SMEs start-ups and entrepreneurs with a focus on the production of electronics, electronic devices or at least parts of these devices. Nevertheless, the empirical data collection activities were covering also large companies that are active in the electronic component market. The geographical scope of the empirical data collection activities was framed through the majority of adjacent BSR countries, namely Estonia, Latvia, Lithuania, Finland and Germany.

The empirical data collection was exclusively online-based, whereby the access to the respective online survey was provided via a specific link (five links for five language versions of the online survey) to the website, where the five translated versions of online survey had been previously implemented and launched. The invitation to the online survey reached the target group via e-mails from the project partners (PPs). In order to gain a sufficiently large response rate some companies were contacted via telephone, during face-to-face meetings, training events or conferences. Accordingly, the data collection process was anonymized, and no one else - with exception of the representatives of the EU project TEST-4-SME - could see the answers or information that had been provided by the participants.

The following key advantages could be perceived through the online-based data collection: (1) ensuring that the survey was carried out anonymously, (2) exclusion of influencing the respondents due to the survey situation, (3) facilitation of respondents' time-based flexibility, and (4) generation of an adequate sample [24]-[27]. Possible disadvantages of the online-based survey could be reduced or eliminated. For instance, in order to prevent misuse in the form of a multiple participation, the inclusion of cookies was conducted [27]. Furthermore, comprehension problems - which can be clarified for example in an oral or telephone survey - could be largely ruled out, since the topic and its essential contents were explained at the beginning of the survey. On the other hand, this issue was also tackled by the circumstance that the previous identification of potential participants was individual performed by each PP according to the definition of the target group. Against this background, it can be assumed that the participants in the survey are familiar with the topic. This was also reflected by the received results of two control questions, where the majority of the participants of the conducted online survey indicated that they "use testing services to test their production" and that they have "awareness of testing services in their own region". This was crucial in order to generate profound results in the frame of examination of gaps in testing services in the BSR $[25]^{2}$.

Moreover, it was indicated that the provided data was always treated confidentially and for further purposes aggregated anonymously in order to make the data usable for research and scientific purposes only. In sum, these given information on the introduction page of the

\footnotetext{
${ }^{1}$ In some cases, the data collection procedure was finished by the end of the year 2018, since some supporting PPs had already acquired a sufficient sample size in their specific country/region.

${ }^{2}$ In the frame of the control question one, where the participants were asked whether they use testing services in order to test their production, in the overall sample, $60.87 \%$ of the participants indicated that they use testing services for their products. In the course of the second control question, participants where asked, whether they have awareness of testing services in their region. $70.44 \%$ of the participants answered that they have knowledge about testing services, which are offered in their region.
} 
online survey resulted in the option for the participant to agree on the indicated consent form and provided information, or not. All this information and the declaration of consent were implemented in order to be in line and to show compliance with the current EU data protection legislation.

\subsection{Data Analysis}

After successful data collection phase, which ended up with 115 responses, seamlessly, data analysis measures were performed. The empirical data analysis activities were finished by the middle of March 20193. The data analysis procedure embraced a two-step approach - data analysis on national level and afterwards on entire BSR level. First, a template for a structured data analysis on country basis was developed and the local results were pre-processed, translated to English and then consolidated. The consolidated BSR survey delivered quantitative results, which had been analysed by statistical methods comprising descriptive and multivariate statistical data analysis - in particular the analysis of variance (ANOVA).

In addition to that, also qualitative research was executed in form of structured interviews with experts. The 12 expert interviews with SME executives covered the regions of Germany, Lithuania and Estonia, and identified tentative reasons for existing gaps in open lab infrastructure and services. The topics of the received answers from the different expert interviews were coded, categorized and then summarize to receive reliable empiric results.

Based on the statistical analysis, a gap analysis was performed through the usage of the "two-component approach" in order to measure the customer satisfaction, which can be used as a guideline for the identification of service gaps [28]. The gap analysis is a special form of a target costing model which is used in value engineering and which tries to align product properties and costs for functionalities realizing these properties [29], [30]. In the case of the gap analysis that is used in marketing the starting point are customer satisfaction measurements, where two approaches are usually pursued simultaneously in the corresponding surveys, asking for importance as well as perceived satisfaction. Thus, in addition to researching the current satisfaction or dissatisfaction of the customers with the service used, the customer's claims will be simultaneously determined, i.e. also the expectations that the customer wishes in advance of the utilization of the performance. For example, in a two-component approach, a questionnaire on customer satisfaction always reveals two questions, one on the importance and one on the current satisfaction of the customer.

This two-component approach allows interpreting the importance as a target value / figure, i.e. as the set point, while the current satisfaction can be understood as the actual value from the customer perspective. From the difference between the values of importance and satisfaction in the answers of the customers, it becomes possible to gain valuable information on the need for action. For instance, if the survey carries out that the customer considers a certain service to be more important than currently realized, there is an acute need for action to increase the present customer satisfaction. The corresponding action portfolio, which builds upon the comparison between importance and satisfaction, with the most important action instructions, can be represented graphically in the form of a customer satisfaction matrix, which is shown in Fig. 1 below.

\footnotetext{
${ }^{3}$ In some cases, the data analysis procedure was already started at the beginning of January 2019, since some responsible PPs had already acquired a sufficient sample size in their specific country/region by the end of the year 2018.
} 


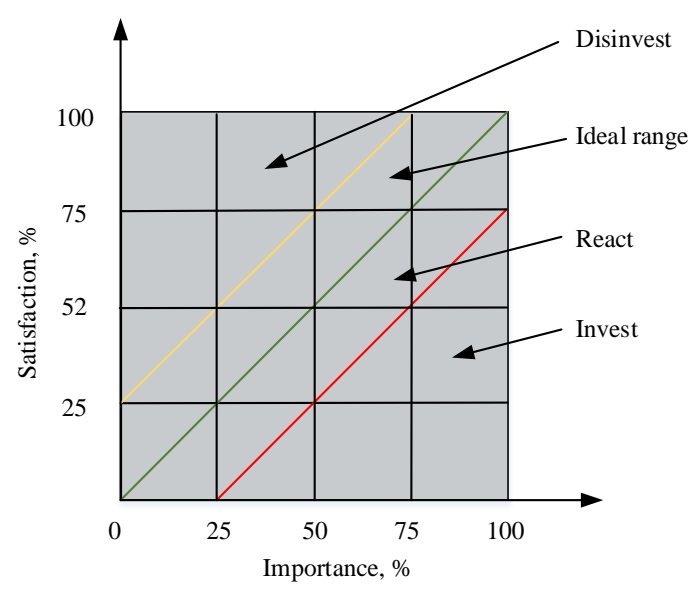

Fig. 1. Customer satisfaction matrix [28].

The ideal range in the relationship between the established satisfaction and the desired importance represents the state in which satisfaction and importance are almost in balance. If the satisfaction exceeds the importance then there is a risk that the relatively high satisfaction scores were achieved with too high investment costs, which is often associated with satisfaction deficits in other important services, so that a possible disinvestment is indicated. Finally, if satisfaction is too low in comparison with importance, there is a need for rapid action to strengthen this service, i.e. an investment is recommended. In order to describe the relationship between satisfaction and importance, in practice the customer satisfaction index is often used as a characteristic parameter [28]:

$$
C S I=100 \cdot \frac{S}{I} \text { in } \%, \text { if } I>0
$$

where

CSI Customer Satisfaction index;

$S \quad$ Satisfaction;

I Importance.

This measure (CSI) represents the ratio of perceived customer satisfaction to the perceived importance of an offered service. By contrasting the empiric satisfaction values of the services with their expected importance values, a comparison of target and actual values for the customer satisfaction analysis is carried out, i.e. it becomes possible to gain a characteristic assessment profile from customer's perspective in form of a strength-weakness analysis, which is well known from management control concepts.

\subsection{Sample Description}

During the data collection phase, 571 companies accessed the online survey via the link to the website. Thereby, 571 represents only the number of companies that have accessed the online survey, even more had been contacted. However, a total of 115 companies have fully 
participated in the underlying survey. Accordingly, this represents a dropout rate of $79.86 \% 4$. The population is made up of companies that produce electronic products and are located in the eligible catchment area of the "Baltic Sea Region Programme 2014-2020", which is further limited in the frame of the performed data collection (online survey) to the inclusion of the five eligible regions/countries: Estonia, Latvia, Lithuania, Finland and Germany. The description of the underlying sample is given in Table 1.

In addition, in the course of the geographical scope of business, the participants were further asked on which international markets they are active, if international markets are of relevance. The results thereof were summarized through a conducted content analysis. Thereby the indicated different international country specific markets were aggregated to continental markets, in order to receive an overview about the most important international markets of electronic producing companies from the BSR. In Table 2, the results thereof were structured by country affiliation or origin of participants, respectively, in comparison to continental markets of business relevance.

As mentioned in the previous sub-chapter "data collection", two control questions were implemented in the online survey in order to figure out, whether the participants have profound knowledge about the relevant examination topic. This was crucial in order to ensure validity of the generated results in the frame of investigation of gaps in testing services in the BSR [25]. The detailed results of these control questions are summarized in Table 3.

TABLE 1. SAMPLE DESCRIPTION

\begin{tabular}{|c|c|c|c|c|c|c|c|c|c|c|c|c|}
\hline & \multicolumn{2}{|c|}{ BSR } & \multicolumn{2}{|c|}{ Estonia } & \multicolumn{2}{|c|}{ Latvia } & \multicolumn{2}{|c|}{ Lithuania } & \multicolumn{2}{|c|}{ Finland } & \multicolumn{2}{|c|}{ Germany } \\
\hline & hi & fi, $\%$ & hi & fi, $\%$ & hi & fi, $\%$ & hi & $\mathrm{fi}, \%$ & hi & $\mathrm{fi}, \%$ & hi & $\mathrm{fi}, \%$ \\
\hline $\begin{array}{l}\text { Number/proportion } \\
\text { of participants }\end{array}$ & 115 & 100.000 & 44 & 100.000 & 15 & 100.000 & 14 & 100.000 & 22 & 100.000 & 20 & 100.000 \\
\hline \multicolumn{13}{|l|}{ Company size } \\
\hline Micro & 38 & 33.043 & 15 & 34.091 & 7 & 46.667 & 7 & 50.000 & 1 & 4.545 & 8 & 40.000 \\
\hline Small or Medium & 65 & 56.522 & 23 & 52.273 & 8 & 53.333 & 7 & 50.000 & 20 & 90.909 & 7 & 35.000 \\
\hline Large & 12 & 10.435 & 6 & 13.636 & 0 & 0.000 & 0 & 0.000 & 1 & 4.545 & 5 & 25.000 \\
\hline \multicolumn{13}{|l|}{ Company age } \\
\hline$x \leq 2$ year & 8 & 6.957 & 3 & 6.818 & 0 & 0.000 & 2 & 14.286 & 0 & 0.000 & 3 & 15.000 \\
\hline $2<x \geq 5$ years & 18 & 15.652 & 6 & 13.636 & 7 & 46.667 & 2 & 14.286 & 1 & 4.545 & 2 & 10.000 \\
\hline $5<x \geq 10$ years & 20 & 17.391 & 9 & 20.455 & 4 & 26.667 & 4 & 28.571 & 2 & 9.091 & 1 & 5.000 \\
\hline$x>10$ years & 69 & 60.000 & 26 & 59.091 & 4 & 26.667 & 6 & 42.857 & 19 & 86.364 & 14 & 70.000 \\
\hline \multicolumn{13}{|c|}{ Geographic scope of business } \\
\hline Local & 24 & 20.870 & 15 & 34.091 & 2 & 13.333 & 2 & 14.286 & 0 & 0.000 & 5 & 25.000 \\
\hline National & 19 & 16.522 & 5 & 11.364 & 3 & 20.000 & 2 & 14.286 & 2 & 9.091 & 7 & 35.000 \\
\hline International & 72 & 62.609 & 24 & 54.545 & 10 & 66.667 & 10 & 71.429 & 20 & 90.909 & 8 & 40.000 \\
\hline \multicolumn{13}{|c|}{ Business activity fields (multiple answer options) } \\
\hline Electronic devices & 77 & 39.286 & 29 & 38.158 & 13 & 54.167 & 9 & 40.909 & 14 & 48.276 & 12 & 26.667 \\
\hline
\end{tabular}

\footnotetext{
${ }^{4}$ The dropout rate in case of the introduction page of the survey is equal to $66.38 \%(\mathrm{hi}=379)$. The main reason for this might be traced back to the circumstance that on the introduction page, the potential participants had been informed that a minimum of data about their company would be collected in the frame of the online survey in order to analyse the needs of different types of enterprises, which could have had a deterrent effect.
} 


\begin{tabular}{lcccccccccccc}
\hline $\begin{array}{l}\text { Materials for } \\
\text { electronical devices }\end{array}$ & $\mathbf{1 3}$ & $\mathbf{6 . 6 3 3}$ & 6 & 7.895 & 1 & 4.167 & 2 & 9.091 & 0 & 0.000 & 4 & 8.889 \\
$\begin{array}{l}\text { Materials for } \\
\text { protection from } \\
\text { electromagnetic field }\end{array}$ & $\mathbf{8}$ & $\mathbf{4 . 0 8 2}$ & 1 & 1.316 & 2 & 8.333 & 0 & 0.000 & 0 & 0.000 & 5 & 11.111 \\
$\begin{array}{l}\text { Parts, components } \\
\text { and/or pieces for } \\
\text { electrical devices }\end{array}$ & $\mathbf{3 1}$ & $\mathbf{1 5 . 8 1 6}$ & 12 & 15.789 & 4 & 16.667 & 4 & 18.182 & 4 & 13.793 & 7 & 15.556 \\
$\begin{array}{l}\text { Computing, ICT } \\
\text { technologies, R\&D }\end{array}$ & $\mathbf{2 9}$ & $\mathbf{1 4 . 7 9 6}$ & 14 & 18.421 & 2 & 8.333 & 1 & 4.545 & 3 & 10.345 & 9 & 20.000 \\
Other & $\mathbf{3 8}$ & $\mathbf{1 9 . 3 8 8}$ & 14 & 18.421 & 2 & 8.333 & 6 & 27.273 & 8 & 27.586 & 8 & 17.778 \\
Total & $\mathbf{1 9 6}$ & $\mathbf{1 0 0 . 0 0 0}$ & 76 & 100.000 & 24 & 100.000 & 22 & 100.000 & 29 & 100.000 & 45 & 100.000 \\
\hline & & & & & & & & & & &
\end{tabular}

TABLE 2. GEOGRAPHICAL SCOPE OF BUSINESS - INTERNATIONAL

\begin{tabular}{|c|c|c|c|c|c|c|c|c|c|c|c|c|}
\hline & \multicolumn{2}{|c|}{ BSR } & \multicolumn{2}{|c|}{ Estonia } & \multicolumn{2}{|c|}{ Latvia } & \multicolumn{2}{|c|}{ Lithuania } & \multicolumn{2}{|c|}{ Finland } & \multicolumn{2}{|c|}{ Germany } \\
\hline & hi & fi & hi & fi & hi & fi & hi & fi & hi & fi & hi & fi \\
\hline \multicolumn{13}{|c|}{ International business } \\
\hline Africa & 2 & 2.273 & 0 & 0.000 & 1 & 7.143 & 1 & 7.143 & 0 & 0.000 & 0 & 0.000 \\
\hline Australia & $\mathbf{0}$ & 0.000 & 0 & 0.000 & 0 & 0.000 & 0 & 0.000 & 0 & 0.000 & 0 & 0.000 \\
\hline Asia & 15 & 17.045 & 7 & 20.000 & 3 & 21.429 & 2 & 14.286 & 2 & 11.765 & 1 & 12.500 \\
\hline Europe & 33 & 37.500 & 15 & 42.857 & 5 & 35.714 & 5 & 35.714 & 5 & 29.412 & 3 & 37.500 \\
\hline $\begin{array}{l}\text { North } \\
\text { America }\end{array}$ & 18 & 20.455 & 9 & 25.714 & 3 & 21.429 & 3 & 21.429 & 3 & 17.647 & 0 & 0.000 \\
\hline $\begin{array}{l}\text { South } \\
\text { America }\end{array}$ & $\mathbf{0}$ & 0.000 & 0 & 0.000 & 0 & 0.000 & 0 & 0.000 & 0 & 0.000 & 0 & 0.000 \\
\hline Worldwide & 20 & 22.727 & 4 & 11.429 & 2 & 14.286 & 3 & 21.429 & 7 & 41.176 & 4 & 50.000 \\
\hline Total & 88 & 100.000 & 35 & 100.000 & 14 & 100.000 & 14 & 100.000 & 17 & 100.000 & 8 & 100.000 \\
\hline
\end{tabular}

TABLE 3. CONTROL QUESTIONS

\begin{tabular}{|c|c|c|c|c|c|c|c|c|c|c|c|c|}
\hline & \multicolumn{2}{|c|}{ BSR } & \multicolumn{2}{|c|}{ Estonia } & \multicolumn{2}{|c|}{ Latvia } & \multicolumn{2}{|c|}{ Lithuania } & \multicolumn{2}{|c|}{ Finland } & \multicolumn{2}{|c|}{ Germany } \\
\hline & hi & fi, $\%$ & hi & $\mathrm{fi}, \%$ & hi & fi, $\%$ & hi & fi, $\%$ & hi & $\mathrm{fi}, \%$ & hi & fi, $\%$ \\
\hline $\begin{array}{l}\text { Number/proportion } \\
\text { of participants }\end{array}$ & 115 & 100.000 & 44 & 100.000 & 15 & 100.000 & 14 & 100.000 & 22 & 100.000 & 20 & 100.000 \\
\hline \multicolumn{13}{|c|}{ Usage of testing services for production } \\
\hline No & 45 & 39.130 & 20 & 45.455 & 6 & 40.000 & 4 & 28.571 & 2 & 9.091 & 13 & 65.000 \\
\hline Yes & 70 & 60.870 & 24 & 54.545 & 9 & 60.000 & 10 & 71.429 & 20 & 90.909 & 7 & 35.000 \\
\hline \multicolumn{13}{|c|}{ Awareness of testing services in own region } \\
\hline No & 34 & 29.565 & 9 & 20.455 & 6 & 40.000 & 5 & 35.714 & 4 & 18.182 & 10 & 50.000 \\
\hline Yes & 81 & 70.435 & 35 & 79.545 & 9 & 60.000 & 9 & 64.286 & 18 & 81.818 & 10 & 50.000 \\
\hline
\end{tabular}

\section{Results}

In order to identify gaps of testing services, the participants had been asked to give their opinion according to the "level of availability of testing infrastructure" and "level of 
accessibility of testing services" in their region. The number of testing services in both fields was equal and embraced 14 different kinds of testing services. The assessment scale corresponded to a five-item scale. This coded item-scale consisted of (1) complete shortage / very low accessibility, (2) poor availability / low accessibility, (3) adequate availability / accessibility, (4) good availability / accessibility, and (5) very good availability / accessibility. Furthermore, in order to avoid distortions in the answers, an alternative answer option has additionally been added, which gave the participants the possibility to indicate that they are "not interested in this type of testing service".

In order to detect gaps of testing services in the region, as a first step, the ANOVA was performed, in order to analyse whether there exist significant differences between the five countries / regions in relation to the evaluation behaviour in case of the individual testing services. By doing so, significant differences between the partial samples could be identified in the frame of the testing service "characterization \& testing of batteries, solar cells \& electrical systems" with $p$-value of 0.00049 ("level of availability of testing infrastructure") and 0.00901 ("level of accessibility of testing services"). Furthermore, a nearly significant difference could be observed in the course of the testing service "material \& compositional characterization, testing \& analysis" with a $p$-value of 0.05868 ("level of availability of testing infrastructure") and 0.09363 ("level of accessibility of testing services"). It should be also noted, that in the case of "shock \& vibration testing" a $p$-value of 0.10727 ("level of availability of testing infrastructure") and in the frame of "calibration, characterization \& measurements optical systems" a $p$-value of 0.13522 "level of accessibility of testing services") were gained, which show a slightly tendency towards significance - depending on where the level of significance is drawn. Therefore, in principle, it could be determined from the ANOVA that there exist significant differences in the partial samples and thus, there exist gaps of testing services in the region. However, the results based on the ANOVA were not as clear as expected. Since the ANOVA cannot show where or in which country the gaps in testing services have occurred, a more in-depth analysis of customer satisfaction using the two-component approach is presented in the following.

Accordingly, deeply rooted in the fact that the online survey followed the two-component approach, at the same time both, the importance and the current perception were asked in the online survey for the same portfolio of testing services; and thus, the resulting target values and actual values represent the assessment of the respective 14 testing services. To be more precise, from the perspective of testing service customers, the "accessibility of testing services" correspond to the satisfaction of the supply and therefore represent the actual values for the individual testing services. Vice versa, the "availability of testing infrastructure" is the equivalent of the importance or demand / interest, and thus is regarded as the target values of the respective testing services. For all these gathered target and actual values, the corresponding arithmetic mean had been calculated, which in each case referred to the fiveitem scale by neglecting the alternative answer option "no interest". In addition, the CSI values were determined for each of the 14 testing services, which were grounded on the arithmetic means of the target and actual values as input variables.

The CSI values deliver indications for the need of action in the course of measures for the increase of customer satisfaction. In the course of the action portfolio on entire BSR level, it can be verified that there is an acute need for action in the frame of the testing service called "energy efficiency testing" (CSI $=89.64 \%$ ). On the other hand, in the course of "shock \& vibration testing" an extraordinary overage is indicated $(\mathrm{CSI}=108.81 \%)$.

In order to draw a clearer picture of the current situation of the testing services, it is necessary to have a closer look on the individual performance on national level. Through this, 
the identification of gaps of testing services in the region is more profound ensured. The respective results are showcased in Fig. 2.

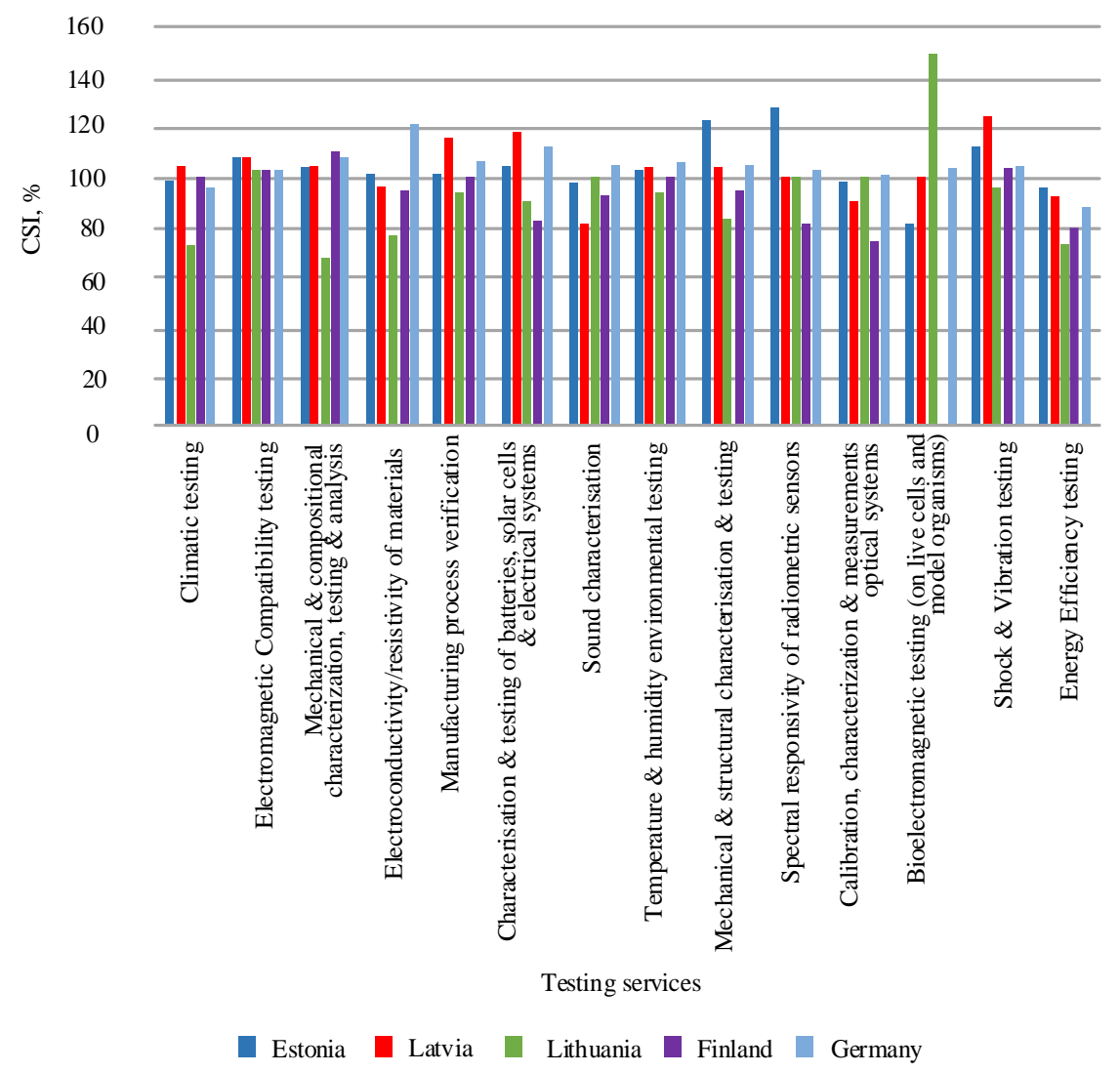

Fig. 2. CSI - national level.

By analysing Fig. 2, it can be stated that in the case of the testing service "climate testing", there is an urgent need for action in Lithuania, since the CSI of $72 \%$ represents a too low satisfaction of customers in comparison to the assessed importance of this testing field. Similarities applies to Lithuania in the course of "material \& compositional characterization, testing \& analysis", since the CSI of $68.42 \%$ represents again a too low satisfaction in comparison to the evaluated importance of this testing service. On the other hand, for Finland, it can be stated that a CSI of $111.11 \%$ in this testing field is slightly too high, since the satisfaction can be evaluated as too high compared with the resulting importance, which points that the relatively high satisfaction score was achieved with too high investment costs. In the testing field "electro-conductivity / resistivity of materials", again, Lithuania exhibits a deficit $(77.38 \%)$, whereby in the case of Germany an overage is visible (121.73\%), which also applies for Latvia in the case of "manufacturing processes verification" $(116.83 \%)$. Regarding the testing service "characterization \& testing of batteries, solar cells \& electrical systems", it is obvious that only for Estonia a moderate outcome is apparent. The CSI value of Finland $(83.33 \%)$ and to a certain extend also in the case of Lithuania $(91.22 \%)$ reveal too low satisfaction scores in comparison to the achieved importance of this testing service. 
In contrast to this, the result for Latvia $(118.52 \%)$ as well as to a certain degree also the one of Germany $(113.08 \%$ ) indicate oversaturation. In the frame of "sound characterization" the need of action is present for Latvia (80 \%) and Finland $(93.33 \%)$, which is in a similar way also slightly visible in the case of Lithuania $(94.44 \%)$ in the frame of offered "temperature \& humidity environmental testing", compared with the achieved heavy deficit of Lithuania in the course of "mechanical \& structural characterization \& testing" (84.62\%). In the latter case ("mechanical \& structural characterization \& testing"), Estonian exhibits a grave overage (122.04\%), whereby the resulting overhang of Estonia in the case of the testing service "spectral responsivity of radiometric sensors" is even higher (128.57\%). In comparison to this, there is need for action for Finish labs, since a CSI value of $81.82 \%$ indicates that the customers are not satisfied with the offered service "spectral responsivity of radiometric sensors". Similarities of deficits apply also in the case of "calibration, characterization \& measurements optical systems" in Finland (74.07\%) and Latvia $(90.91 \%)$. Due to the low interest of especially Finish companies for "bio-electromagnetic testing (on live cells and model organisms)", the respective CSI value was not determinable, whereby for Estonia a deficit $(81.25 \%)$ and for Lithuania a great overage $(150 \%)$ was detectable.

The big variance between the target and actual values in the service area "shock \& vibration testing", which was noticed in the overall sample BSR, has his origin in the strong overhang of satisfaction scores in comparison to the evaluated importance by customers in Estonia $(112.38 \%)$ and Latvia (124.22\%). Against this, the identified deficit of the BSR in the "energy efficiency testing" field, can be traced back to the poor assessment of satisfaction by companies from Latvia (93.33\%), Lithuania (73.33\%), Finland (80\%) and Germany $(87.93 \%)$.

These predications are also confirmed through the evaluation of the results of the customer satisfaction analysis in form of a target / actual comparison by using the arithmetic mean values. By analysing the target / actual comparison, it can be detected that the expected requirement to the service "energy efficiency testing" could not be met, since the current valuation from the customers perspective is with 0.34 valuation points below the desired target score. On the other hand, the positive gap of about 0.26 valuation points between the actual and target value in the case of the service "shock \& vibration testing" is particularly high. For the other 12 testing services, there are no such serious deviations as for "energy efficiency testing" and "shock \& vibration testing".

These previous findings are also validated by the comparison of the differences of the arithmetic means - which is exemplified here by the results on entire BSR level in Fig. 3, which visualize the target / actual comparison from another perspective. In contrast to the direct target / actual comparison, the consideration of the differences in the arithmetic mean values also deliver that the aggregated and sophisticated view of the results in the case of the entire BSR indicates a possible need for action in the frame of the service "climatic testing".

Furthermore, on national level, it is noticeable that especially the differences of the target and actual values in the case of Lithuania are quite unbalanced and show great outliers in comparison to the results of the other four countries. Moreover, in the case of the related Finish results, it can be stated that in the course of some testing service fields, namely "characterization \& testing of batteries, solar cells \& electrical systems", "spectral responsivity of radiometric sensors", "calibration, characterization \& measurements optical systems" and "energy efficiency testing", the deviations between the target and actual values are quite high, which underpinned once again an acute need for action for laboratories and testing institutions in Finland. In all cases shown here, the comparison of the target and the 
actual values or the resulting CSI values represent a current presentation of the strengths and weaknesses of testing services offered by laboratories in the BSR from customer perspective.

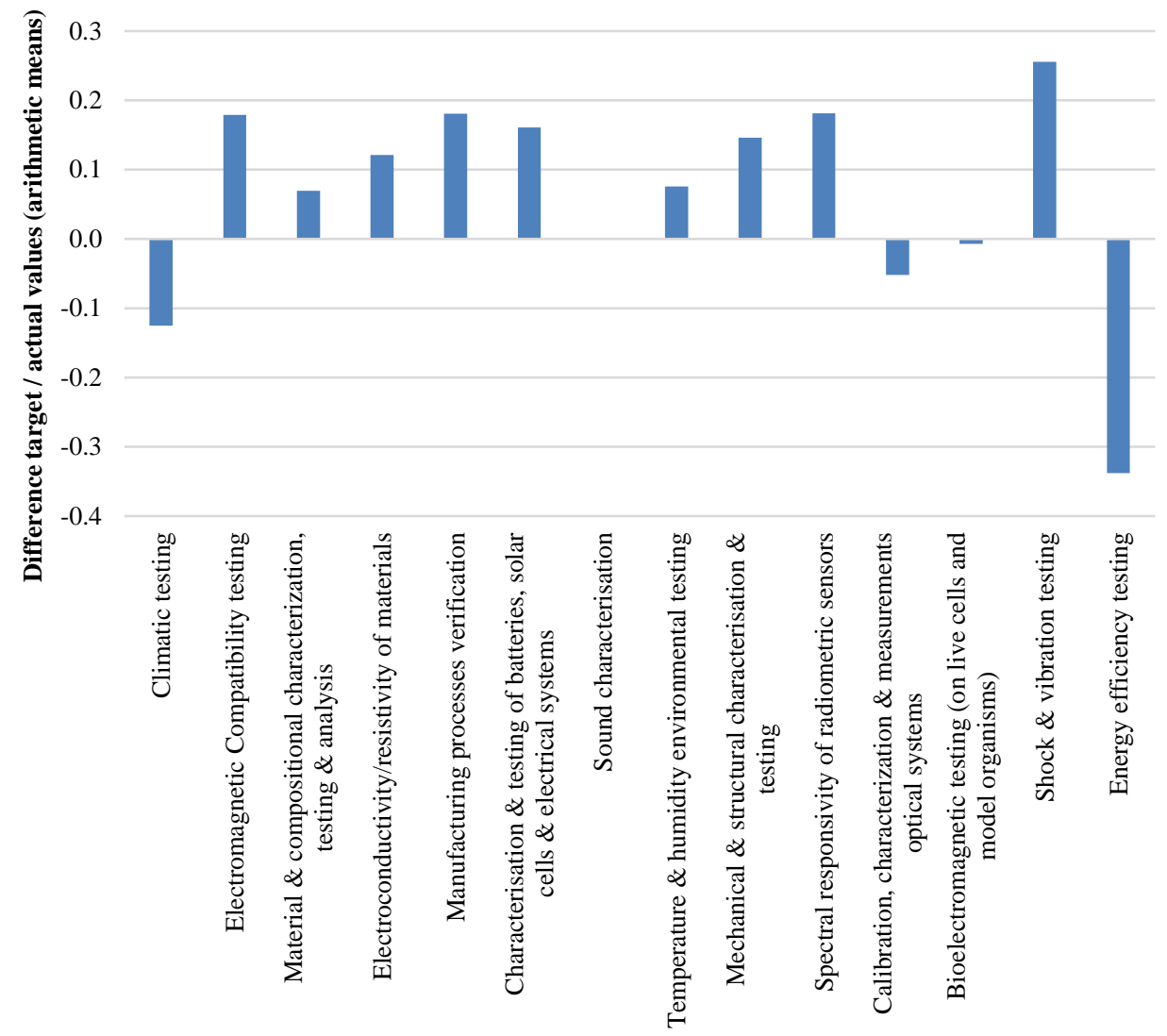

Testing services

Fig. 3. Difference target/actual values (arithmetic means) - BSR.

For the analysis of the reasons for the perceived low availability of testing infrastructure and low accessibility of testing services in the region, expert interviews with CEOs and other executives of electronic products producing companies have been realized. The expert interviews revealed that the main reasons for a low availability of testing infrastructure in the region is often seen in the general low demand for testing services, followed by the lack of qualified personnel, who can carry out the required tests. Companies from Estonia further indicated that it is not easy to figure out who is offering testing services and that the legislation is still in creation, which can be both regarded under the umbrella of missing awareness.

Further national peculiarities were identified during expert interviews with Lithuanian companies, who stated that for their own purposes the available measurement equipment is not adapted to the next generation (e.g. for tests on solar cells and modules) and that the nearest available infrastructure is in Germany. Another Lithuanian company mentioned that in their immediate surrounding, there are no accredited institutions, who are capable of 
performing optical and temperature measurements. Additionally, a German company specified that due to political interest, specific tests are not wanted, which from company's' perspective are normally desirable. Other German companies indicated that reasons for low availability of testing infrastructure in their region can be related to high costs, historical development, the niche application of own products and that no test institutes are specialized in aviation technology and loads, whereby the two latter cases are also attributable to the lack of qualified personnel.

Two other major reasons for a low accessibility to the required testing services in the region, named by executives of electronic components producing companies were high costs for claiming test services, as well as the low awareness of either utilization rules or frame conditions of the available infrastructure. Less stated reasons were high utilization rate of the required testing infrastructure and long associated waiting time, as well as the restricted or limited accessibility imposed by owners of the testing infrastructure. Estonian companies mentioned that necessary equipment is not existing in Estonian labs, and that there is a lack of demand, experience and again the issue of legislation. The missing awareness was also already mentioned in the survey and were mainly pointed out by Estonian, Latvian and Lithuanian companies. The survey also pointed out a chicken-and-egg-problem since some companies stated that generally there is not enough test supply due to the small number of labs, whereas other companies, especially from Lithuania blamed the low demand for existing gaps. Finally, a German company mentioned that especially laboratories have to face high fix costs for the purchase of (up-to-date) equipment, which has a deterrent effect on testing institutions and their offer due to risk aversion. The expert interviews revealed that further research has to be realized to get a more detailed picture

\section{Discussion AND CONCluSion}

In this study the identification and analysis of gaps in testing services in the BSR was investigated. The research revealed that there exist significant differences in testing supply in the BSR and the participating member states and thus, there exist gaps of testing services in the region. Moreover, through the two-component approach, it was detected that in the BSR, especially in the frame of the testing service "energy efficiency testing" there is need for action in form of investments. Against this, the research further showed that in the course of the testing service "shock \& vibration testing" an oversaturation is indicated in the region, which leads to the recommendation of a potential disinvestment, since in this specific testing service field surpassingly satisfaction was achieved through customers valuation, namely electronic products producing SMEs, which is often associated with satisfaction deficits in other important services, like "energy efficiency testing".

The findings on entire BSR level represent the overall aggregated results or holistic picture, respectively, which consist of the detail results of the individual investigated five countries, namely Estonia, Latvia, Lithuania, Finland and Germany. Accordingly, the big variance in the frame of the testing service "shock \& vibration testing", has its origin in the strong overhang of satisfaction scores - in comparison to the evaluated importance - by customers in Estonia and Latvia. Against this, the identified deficit of the BSR in the "energy efficiency testing" field, can be traced back to the poor assessment of satisfaction by companies from Latvia, Lithuania, Finland and Germany. Furthermore, the differences of the arithmetic means (target and actual values) on BSR level revealed in addition a possible need for action in the frame of the service "climatic testing". 
In all cases shown here, the comparison of the target and the actual values or the resulting CSI values denote a current presentation of the strengths and weaknesses of testing services offered by laboratories in the BSR from customer perspective. In the globalized knowledge society, competitiveness and prosperity of regions depend on local strengths and innovation power of local economy, i.e. success in the future will be for those companies and urban or rural areas that are able reach global standards and join global networks and markets [31]. Therefore, the access to knowledge, skills and innovation at the local level has become as important as the infrastructure. Accordingly, university-business cooperation as nucleus for the creation of regional innovation networks between SMEs and regional R\&D institutions become a key and driving force for development of local economy [32] and a more sustainable society [30]. Regional development is an innovation process that significantly depends on interaction. Interaction is the basis for acquiring knowledge and innovation and thus for the economic well-being of regions. Therefore, successful innovation is based on the structures and types of interaction between knowledge providers, distributors and users [31].

The dense network of universities and R\&D institutions in the BSR bears high potential for sustainable product development. The project "TEST-4-SME" together with its online survey and expert interviews give an insight view on the state of play of the status of collaboration between SME and research institutions from different BSR countries in the field of electronics and electronic equipment. The survey reveals that there exist already several "open lab"-based regional innovation networks in BSR but there are also still significant gaps between demand and supply. Despite the fact, that university researcher collaborate closely with SMEs and SMEs are able to access testing labs and services in the area of electronic product development, the shortcomings in climate issues as well as in energy saving topics of new products and the perceived reasons for this circumstances from customer perspective were highlighted in this research.

Since regional development is an innovation process that significantly depends on interaction, especially in the context of smart specialization strategies, more interaction between SME sector and regional R\&D institutions is necessary for the economic prosperity of the regions. The cluster concept of Porter is pointing out the regional aspects by defining a cluster as "... a geographically proximate group of interconnected companies and associated institutions in a particular field, linked by commonalities and complementarities" [33]. The success or the competitiveness of such a cluster is influenced to large extent by these commonalities and complementarities, i.e. its internal characteristics. Most literature on clusters is stressing the spatial aspects by explaining why such groupings of firms emerge in a specific place and why it is bound to that particular place. However, a cluster is also determined by its external environment, i.e. the geographical setting and environments. Some often mentioned advantages of the development of clusters are that they allow companies to be more productive and innovative than they could be if they were isolated, i.e. the cluster approach is important because it reduces the entry barriers for new business creation relative to other locations [34].

By focusing on networking and regional innovation aspects, Goddard developed the idea of regional knowledge or innovation networks where only those enterprises will be successful in a globalized knowledge economy that meet global standards, join global networks and create operational models that match quickly changing market trends. The competitiveness of the enterprise depends on skilled employees and innovative products or services [31], [32]. Thus, the availability of knowledge, innovation and skills has become locally as important as the infrastructure so that collaborative innovation activities between SME sector and research institutions represent key success factors to compete in the global economy. 
The research results highlight, that BSR is on the right track to keep its vanguard position in innovation of sustainable product development. The differences between the considered regions were detectable to varying degrees. The general weak point that turned out was located in issues related to climate and energy savings which have to be mitigated as soon as possible because these topics represent exactly the key areas for sustainable product development, especially for the case of electronic products. By removing these hinders a sustainable success of electronic product developments of SMEs in the BSR seems to be achievable.

\section{ACKNOWLEDGEMENT}

This work has been supported by the European Regional Development Fund (Baltic Sea Region Programme 2014-2020) within the project "Laboratory Network for Testing, Characterisation and Conformity Assessment of Electronic Products developed by SMEs - TEST-4-SME". Special thanks also go to the lead partner and all other project partners of the EUproject TEST-4-SME for supporting the data collection in the frame of the survey - especially Mari Allik and Tiia Lillemaa (Tartu Observatory and University of Tartu), Egidija Rainosalo (Centria University of Applied Sciences) and Martynas Bertašius (Applied Research Institute for Prospective Technologies).

\section{REFERENCES}

[1] Gerlitz L., Philipp R., Beifert A. Smart and Sustainable Cross-Sectoral Stakeholder Integration into Macro-Regional LNG Value Chain. In: Kabashkin I., Yatskiv I., Prentkovskis O. (eds) Reliability and Statistics in Transportation and Communication. RelStat 2017. Lecture Notes in Networks and Systems. Springer 2017:36:112-126. doi:10.1007/9783-319-74454-4_11

[2] State of the Region Report. Edit: Ketels C., Pedersen H. J., Olsson M. State of the Region Report: The Top of Europe - A Competitive Baltic Sea Region: Ready for the Future? Copenhagen: Baltic Development Forum (BDF), 2017.

[3] EC. EU Strategy for the Baltic Sea Region, 2018 [Online]. [Accessed 16.03.2019]. Available: https://ec.europa.eu/regional_policy/sources/cooperate/baltic/pdf/factsheet/factsheet_eusbr_en.pdf

[4] Hermann S. Hidden Champions: Speerspitze der deutschen Wirtschaft (in German). Wiesbaden: Zeitschrift für Betriebswirtschaft (ZfB) 1990:60(9):875-890.

[5] Hermann S. Hidden Champions of the 21st Century: Success Strategies of Unknown World Market Leaders. London: Springer, 2009.

[6] EC. Regional policy for smart growth of SMEs: Guide for Managing Authorities and bodies in charge of the development and implementation of Research and Innovation Strategies for Smart Specialisation, 2013 [Online]. [Accessed 16.03.2019]. Available: http://ec.europa.eu/regional_policy/sources/docgener/studies/pdf/sme_guide/sme_guide_en.pdf

[7] EC. Entrepreneurship 2020 Action plan - reigniting the entrepreneurial spirit in Europe. Brussels, 2013.

[8] EC. European Innovation Scoreboard (2017) [Online]. [Accessed 16.03.2019]. Available: http://ec.europa.eu/DocsRoom/documents/24829

[9] Eurostat. Statistics on small and medium-sized enterprises: Statistics Explained (2018) [Online]. [Accessed 16.03.2019]. Available: https://ec.europa.eu/eurostat/statistics-explained/pdfscache/45509.pdf

[10] Global Innovation Index (2018) [Online]. [Accessed 16.03.2019]. Available: https://www.globalinnovationindex.org

[11] RIS3. Guide to Research and Innovation Strategies for Smart Specialisation (RIS3). Brussels: EC, 2012.

[12] Hirsikoski A., Koski A., Prause G. Promoting Universities' 3rd Task - Recommandations for University-Business Cooperation. Baltic Business and Socio-Economic Development. Berlin: Berliner Wissenschafts-Verlag, 2008:351-367.

[13] Prause G. Regional Networking as Success Factor in the Transformation Processes of Maritime Industry Experiences and Perspectives from Baltic Sea Countries. Wismar: Wismar University, 2010.

[14] Prause G. Smart Specialization and EU Eastern Innovation Cooperation: A Conceptual Approach. Baltic Journal of European Studies 2014:4(1):3-19. doi:10.2478/bjes-2014-0001

[15] Prause G. University - Business Interaction in Times of Demographic Change. Innovations 2015:1(195):78-81.

[16] Forecast of Global Electronic Components Players Market 2023 (2018) [Online]. [Accessed 16.03.2019]. Available: https://www.marketresearchreports.com/mrrpb2/forecast-global-electronic-components-players-market-2023

[17] Hardiman N., Dietz K. C., Bride I., Passfield L. Pilot testing of a sampling methodology for assessing seed attachment propensity and transport rate in a soil matrix carried on boot soles and bike tires. Environmental management 2017:59(1):68-76. doi:10.1007/s00267-016-0773-4 
[18] OECD. Top Barriers and Drivers to SME Internationalisation. Report by the OECD Working Party on SMEs and Entrepreneurship. OECD, 2009.

[19] Macgregor N. A., van Dijk N. Adaptation in practice: how managers of nature conservation areas in eastern England are responding to climate change. Environmental management 2014:54(4):700-719. doi:10.1007/s00267-014-0254-6

[20] Kruitwagen S., Reudink M., Faber A. Pragmatics of Policy: The compliance of Dutch environmental policy instruments to European Union standards. Environmental management 2009:43(4):673-681. doi:10.1007/s00267-008-9248-6

[21] Blumberga A., Timma L., Blumberga D. System dynamic model for the accumulation of renewable electricity using power-to-gas and power-to-liquid concepts. Environmental and Climate Technologies 2015:16(1):54-68. doi:10.1515/rtuect-2015-0012

[22] Bariss U., et al. System Dynamics Modeling of Households' Electricity Consumption and Cost-Income Ratio: a Case Study of Latvia. Environmental and Climate Technologies 2017:20(1):36-50. doi:10.1515/rtuect-2017-0009

[23] Vigants E., et al. Modelling of Technological Solutions to 4th Generation DH Systems. Environmental and Climate Technologies 2017:20(1):5-23. doi:10.1515/rtuect-2017-0007

[24] O'Leary Z. The essential guide to doing your research project. Sage, 2017.

[25] Döring N., Bortz J. Forschungsmethoden und Evaluation (in German). Wiesbaden: Springerverlag, 2016.

[26] Diekmann A. Empirische Sozialforschung: Grundlagen, Methoden, Anwendungen (in German). 18. Aufl. Hamburg, 2007.

[27] Schnell R., Hill P. B., Esser E. Methoden der empirischen Sozialforschung (in German), 2004.

[28] Prause G. GAP-Analyse im marktorientierten Controlling (in German). Controlling-Berater (99-128). Freiburg: Haufe Verlag, 2003.

[29] Cooper R., Slagmulder R. Develop Profitable New Products with Target Costing. Sloan Management Review. Cambridge 1999:40(4):23-33.

[30] Cooper R., Slagmulder R. Target Costing and Value Engineering, new edition. Taylor \& Francis, 2017.

[31] Goddard J. Universities and Regional Development: An Overview. The background paper for the OECD Project on The Response of Higher Education to Regional needs, 1997.

[32] Goddard J. The Response of HEIs to Regional Needs (2000) [Online]. [Accessed 16.03.2019]. Available: http://www.oecd.org/dataoecd/40/25/34407585.pdf

[33] Porter M. E. Locations, clusters, and company strategy. The Oxford handbook of economic geography. UK: Oxford, 2000:253, 274.

[34] Meier zu Köcker G. Clusters in Germany. Berlin: Institute for Innovation and Technology, 2008. 